OPEN ACCESS

Edited by:

Bethan E. Phillips,

University of Nottingham,

United Kingdom

Reviewed by:

Alessandro Capucci,

Marche Polytechnic University,

John Williams,

Royal Derby Hospital,

United Kingdom

*Correspondence:

J. Alberto Neder

alberto.neder@queensu.ca

Specialty section:

This article was submitted to Clinical and Translational Physiology, a section of the journal

Frontiers in Physiology

Received: 15 April 2020 Accepted: 01 March 2021 Published: 18 March 2021

Citation:

Neder JA, Phillips DB, Marillier M,

Bernard A-C, Berton DC and

O'Donnell DE (2021) Clinical

Interpretation of Cardiopulmonary

Exercise Testing: Current Pitfalls and

Limitations.

Front. Physiol. 12:552000.

doi: 10.3389/fphys.2021.552000

\section{Clinical Interpretation of Cardiopulmonary Exercise Testing: Current Pitfalls and Limitations}

\author{
J. Alberto Neder"*, Devin B. Phillips ${ }^{1}$, Mathieu Marillier ${ }^{1}$, Anne-Catherine Bernard ${ }^{1}$, \\ Danilo C. Berton ${ }^{2}$ and Denis E. O'Donnell'
}

'Laboratory of Clinical Exercise Physiology and Respiratory Investigation Unit, Queen's University and Kingston General Hospital, Kingston, ON, Canada, ${ }^{2}$ Division of Respirology, Federal University of Rio Grande do Sul, Porto Alegre, Brazil

Several shortcomings on cardiopulmonary exercise testing (CPET) interpretation have shed a negative light on the test as a clinically useful tool. For instance, the reader should recognize patterns of dysfunction based on clusters of variables rather than relying on rigid interpretative algorithms. Correct display of key graphical data is of foremost relevance: prolixity and redundancy should be avoided. Submaximal dyspnea ratings should be plotted as a function of work rate (WR) and ventilatory demand. Increased work of breathing and/or obesity may normalize peak oxygen uptake $\left(\mathrm{V}_{2}\right)$ despite a low peak WR. Among the determinants of $\dot{\mathrm{V}}_{2}$, only heart rate is measured during non-invasive CPET. It follows that in the absence of findings suggestive of severe impairment in $\mathrm{O}_{2}$ delivery, the boundaries between inactivity and early cardiovascular disease are blurred in individual subjects. A preserved breathing reserve should not be viewed as evidence that "the lungs" are not limiting the subject. In this context, measurements of dynamic inspiratory capacity are key to uncover abnormalities germane to exertional dyspnea. A low end-tidal partial pressure for carbon dioxide may indicate either increased "wasted" ventilation or alveolar hyperventilation; thus, direct measurements of arterial (or arterialized) $\mathrm{PO}_{2}$ might be warranted. Differentiating a chaotic breathing pattern from the normal breath-by-breath noise might be complex if the plotted data are not adequately smoothed. A sober recognition of these limitations, associated with an interpretation report free from technicalities and convoluted terminology, is crucial to enhance the credibility of CPET in the eyes of the practicing physician.

Keywords: exercise, dyspnea, lung function, cardiopulmonal capacity, exercise test interpretation

\section{INTRODUCTION}

Cardiopulmonary exercise testing (CPET) might be helpful in uncovering the causes of exercise intolerance in patients with (or at risk of) cardiorespiratory diseases (Marciniuk et al., 2013). In the pulmonology practice, CPET is usually requested as part of the work-up for unexplained or "out-of-proportion" dyspnea (Neder et al., 2019a). The test, however, rarely pinpoints to a specific diagnosis; thus, it should be better considered as part of the initial assessment to guide further investigative efforts (if required). Unfortunately, however, CPET remains poorly 
understood and, therefore, largely underused in clinical practice. Apart from operational issues (e.g., high costs, limited availability, and poor reimbursement relative to time spent on the test), there are several shortcomings on testing interpretation which have not helped to improve this state of affairs (Neder et al., 2018b). In this concise Perspective, some of these pitfalls and challenges are outlined: owing to the absence of large randomized trials exploring CPET limitations, they were selected based on our long-standing experience with CPET reading and teaching. Moreover, we focused on the limitations more likely to impact on clinical-decision making (Table 1). Of note, we specifically

TABLE 1 | Selected pitfalls and limitations on cardiopulmonary exercise testing (CPET) interpretation which are more likely to negatively impact on clinicaldecision making in respiratory medicine.

\begin{tabular}{|c|c|c|}
\hline Pitfall/limitation & $\begin{array}{l}\text { Potential } \\
\text { consequence }\end{array}$ & $\begin{array}{l}\text { Recommended } \\
\text { approach }\end{array}$ \\
\hline $\begin{array}{l}\text { Over-Reliance on Rigid } \\
\text { Interpretative } \\
\text { Algorithms }\end{array}$ & $\begin{array}{l}\text { Misdiagnosis of the } \\
\text { mechanisms leading } \\
\text { to exercise intolerance }\end{array}$ & $\begin{array}{l}\text { Identify cluster of findings } \\
\text { indicative of syndromic } \\
\text { patterns of dysfunction }\end{array}$ \\
\hline $\begin{array}{l}\text { Incorrect Display of } \\
\text { Graphical Data }\end{array}$ & $\begin{array}{l}\text { Distraction and } \\
\text { redundancy }\end{array}$ & $\begin{array}{l}\text { Focus on the dynamic } \\
\text { relationships more likely } \\
\text { to expose the patterns of } \\
\text { dysfunction }\end{array}$ \\
\hline $\begin{array}{l}\text { Considering Dyspnea } \\
\text { a Secondary Outcome }\end{array}$ & $\begin{array}{l}\text { Poor diagnostic yield } \\
\text { in patients under } \\
\text { investigation for } \\
\text { indetermined dyspnea }\end{array}$ & $\begin{array}{l}\text { Obtain submaximal } \\
\text { dyspnea scores which } \\
\text { should be expressed as a } \\
\text { function of both work rate } \\
\text { and ventilation }\end{array}$ \\
\hline $\begin{array}{l}\text { Misinterpretation of a } \\
\text { "Preserved" Peak } \dot{\mathrm{V}} \mathrm{O}_{2} \\
\text { as Evidence of } \\
\text { Normality }\end{array}$ & $\begin{array}{l}\text { False negative for } \\
\text { exercise intolerance }\end{array}$ & $\begin{array}{l}\text { Carefully review all available } \\
\text { data, even in the presence } \\
\text { of a "preserved" peak } \dot{\mathrm{V}}_{2}\end{array}$ \\
\hline $\begin{array}{l}\text { Ignoring the Effects of } \\
\text { Obesity on the } \\
\Delta \dot{\mathrm{V}} \mathrm{O}_{2} / \Delta \text { Work Rate } \\
\text { Relationship }\end{array}$ & As above & $\begin{array}{l}\text { As above; value potential } \\
\text { decrements in peak work } \\
\text { rate }\end{array}$ \\
\hline $\begin{array}{l}\text { Failure to Recognize } \\
\text { the Poor Diagnostic } \\
\text { Performance of CPET } \\
\text { in Indicating Cardiac } \\
\text { Disease }\end{array}$ & $\begin{array}{l}\text { Misdiagnosis of } \\
\text { potential } \\
\text { cardiovascular } \\
\text { abnormalities }\end{array}$ & $\begin{array}{l}\text { A cautious, non- } \\
\text { committal approach when } \\
\text { ruling in or out a cardiac } \\
\text { disease when the pre-test } \\
\text { likelihood of disease is } \\
\text { unclear }\end{array}$ \\
\hline $\begin{array}{l}\text { Misdiagnosis of } \\
\text { Mechanical-Ventilatory } \\
\text { Limitation }\end{array}$ & $\begin{array}{l}\text { Failure to recognize an } \\
\text { etiologic role for "the } \\
\text { lungs" in limiting the } \\
\text { subject }\end{array}$ & $\begin{array}{l}\text { Routine measurement of } \\
\text { dynamic IC (operating } \\
\text { lung volumes) }\end{array}$ \\
\hline $\begin{array}{l}\text { Under-Recognition of } \\
\text { the Limitations of } \\
\text { Non-invasive } \\
\text { Assessment of } \\
\text { Pulmonary Gas } \\
\text { Exchange }\end{array}$ & $\begin{array}{l}\text { Over- or under-calling } \\
\text { of gas exchange } \\
\text { inefficiency for } \mathrm{O}_{2} \text { or } \\
\mathrm{CO}_{2}\end{array}$ & $\begin{array}{l}\text { Recognize that } \\
\text { measurements of arterial } \\
\text { (or arterialized) blood } \\
\text { gases might be warranted }\end{array}$ \\
\hline $\begin{array}{l}\text { Over- or Under } \\
\text { Recognition of } \\
\text { Chaotic Breathing } \\
\text { Pattern/Dysfunctional } \\
\text { Breathing }\end{array}$ & $\begin{array}{l}\text { Misdiagnosis of } \\
\text { behavioral/ } \\
\text { psychogenic } \\
\text { abnormalities }\end{array}$ & $\begin{array}{l}\text { Adequate data } \\
\text { smoothing; apply a } \\
\text { gestalt approach to } \\
\text { breathing pattern analysis }\end{array}$ \\
\hline
\end{tabular}

$\dot{\mathrm{VO}}_{2}$, oxygen uptake; IC, inspiratory capacity. assume that the reader is already familiar with clinical CPET interpretation; thus, a thorough discussion of interpretative strategies is beyond the scope of this viewpoint article. When feasible, we provide a brief account of the available strategies to avoid key interpretative mistakes (Table 1). If the limitations are deemed insurmountable at this point in time, we caution the reader that the best (and more honest) approach is to refrain from testing over-interpretation. Finally, representative examples are not provided due to space constraints.

\section{DISCUSSION}

\section{Over-Reliance on Rigid Interpretative Algorithms}

There is a pervasive sense that, in similarity with pulmonary function tests, CPET can be meaningfully interpreted considering some dichotomous decision nodes in a hierarchic evaluation tree. In fact, if any, the clinical interpretation of CPET is full of chance nodes: from these nodes, one can only infer the meaning of a certain result given a set of pre-existing conditions. In other words, no variable holds discriminative properties when seen in isolation, i.e., without a proper estimation of the pre-test likelihood of abnormality (Bayes theorem). More realistically, cluster of findings may indicate the presence of certain patterns: (a) a normal maximal or sub-maximal test, (b) obesity, (c) $\mathrm{O}_{2}$ delivery/utilization impairment, (d) mechanical-ventilatory impairment, (e) pulmonary gas exchange impairment, and (f) dysfunctional breathing-hyperventilation disorder (Neder et al., 2018a). The referring physician should be specifically aware that individual features overlap across diseases. It is the referring physician's responsibility to amalgamate the described pattern(s) of abnormalities on his/ her diagnostic plan or prognostic assessment. Although these recommendations seem rather obvious, they are not easily implemented in practice either because: (a) the requester overestimates the test sensitivity/specificity and/or (b) the reader fails to recognize its important limitations. A detailed account of testing interpretation in light of these precautionary considerations is provided by Neder et al. (2018a).

\section{Incorrect Display of Graphical Data}

The great majority of CPETs performed by respiratory patients are symptom-limited. Thus, appreciation of the sensory responses to exercise is an integral part of testing interpretation (O'Donnell et al., 2019). The fundamental task of the reader is to select the more appropriated dependent variables in response to their physiological determinants (or, at least, their closest correlates) taken into consideration the principles of biological plausibility and simplicity (Occam's razor principle). In order to maximize the yield of information and minimize distraction, redundancy must be avoided. Although rapidly-incremental tests (frequently following a ramp forcing regimen; Laveneziana et al., 2017) are almost universally used nowadays, in practice, there is an ample variability in the rates of work increment and stages duration across laboratories. Thus, work rate (WR) and time 
might not always be the best independent variables to judge the response normalcy in individual subjects. The test is based on the fundamental physiological principle that the heart and the lungs ultimately support the uptake of $\mathrm{O}_{2}$ and release of $\mathrm{CO}_{2}$ - which vary markedly for a given work rate or testing time elapsed. Thus, it could be argued that metabolic-cardiovascular responses, minute ventilation $(\dot{\mathrm{VE}})$, and lung mechanics/breathing pattern in the $y$-axis are better expressed relative to their closest determinants in the $x$-axis, i.e., oxygen uptake $\left(\mathrm{V}_{2}\right.$; Whipp and Ward, 1982), carbon dioxide output ( $\dot{\mathrm{VCO}}_{2}$; Whipp, 1977), and VंE (O’Donnell et al., 2017), respectively.

The Wasserman et al. (1987) nine-panels remain the most popular display. It has, however, important limitations which are frequently overlooked (Dumitrescu and Rosenkranz, 2017):

- the panels are heavily biased to depict metabolic/cardiovascular responses: not less than five graphs are basically devoted to the identification of gas exchange and ventilatory thresholds (Wasserman et al., 1973; Beaver et al., 1986);

- $\dot{\mathrm{VO}}_{2}$ and work rate are both expressed as a function of time. Thus, the fundamental relationship of clinical interest $\left[\mathrm{V}_{2}\right.$ (y) vs. work rate $(x)$; Whipp and Ward, 1982] is not shown. Even if $\dot{\mathrm{VO}}_{2}$-to-work rate ratio is correctly scaled to $10: 1$, significant departures from linearity in $\mathrm{VO}_{2}$ (i.e., lack of parallel increase in $\mathrm{VO}_{2}$ as related to work rate) might not be readily apparent in patients with poor exercise tolerance;

- tidal volume (VT) is plotted as a function of $\dot{\mathrm{V}} \mathrm{E}$. VT is also compared to vital capacity (VC) and resting inspiratory capacity (IC), whereas maximal voluntary ventilation (MVV) is shown as the upper limit for $\dot{V}_{E}$. Resting IC, however, is not the correct benchmark to contrast against the $\mathrm{VT}_{\mathrm{T}}$ trajectory as IC usually increases with exercise in healthy subjects or decreases in patients showing expiratory flow limitation (Guenette et al., 2013). VC is substantially greater than IC and the former does not allow a clear recognition of the limits for VT expansion, i.e., exercise IC (O'Donnell et al., 2019). MVV is not a consistent ceiling for a VंE increase and severe dyspnea might arise in patients with still-preserved breathing reserve (Neder et al., 2019a,b; see also Misdiagnosis of Mechanical-Ventilatory Limitation section; Figure 1); and

- the operating lung volumes and dyspnea readings are ignored (see also Considering Dyspnea a Secondary Outcome section).

Alternative displays which avoid these errors and omissions are provided elsewhere (O'Donnell et al., 2017, 2019).

\section{Considering Dyspnea a Secondary Outcome}

The burden to provide a resolution to complex cases of persistent shortness of breath is frequently directed to the pulmonologist (Mahler and O'Donnell, 2015). CPET is a non-invasive procedure which was meant to uncover the causes of exertional breathlessness (Wasserman and Whipp, 1975; Wasserman et al., 1987; Jones, 1988; Weisman and Zeballos, 1996). Indeed, the test measures a multitude of physiological responses important for the genesis of the symptom; thus, at least theoretically, CPET is well-suited to the task (Arena and Sietsema, 2011). In this context, it is rather axiomatic that a special attention should be given to the measurement and interpretation of dyspnea scores. Unfortunately, this is more an exception than a rule in most clinical laboratories nowadays.

In order to fully recognize the advantages of incorporating dyspnea readings on CPET interpretation, it is instructive to consider some basic neurobiological concepts. At a close inspection, exertional dyspnea boils down to a heightened sense of inspiratory load (Campbell and Howell, 1963; Killian and Campbell, 1983). More specifically, the respiratory controller (i.e., pontine-medullary centers and their cortical-limbic connections) continuously appraise "how much ventilation" is performed at a given point in the time. Such quantitative perspective of the load is influenced by chemo-stimulation of central and peripheral receptors (Plataki et al., 2013) and the efferent motor output to the inspiratory muscles (Killian and Campbell, 1983). In the absence of critical mechanical constraints, increased reflex chemostimulation (Plataki et al., 2013) translates into excessive ventilatory response relative to metabolic demand (Neder et al., 2015; Rocha et al., 2017). Consequently, when the increased drive to breathe can be freely converted into the act of breathing, patients tend to report higher dyspnea for a given work rate but similar dyspnea for a given $\dot{V}$ e compared to normal subjects (Kearon et al., 1991; Killian et al., 1992). Conversely, when VT becomes positioned close to the upper reaches of the S-shaped pressure-volume relation of the relaxed respiratory system, compliance decreases, the inspiratory muscles are functionally weakened, and intolerable dyspnea quickly ensues. As a corollary, dynamic mechanical constraints lead to higher dyspnea ratings as a function of both work rate and $\dot{V}_{E}$ (O'Donnell et al., 2019; Plachi et al., 2020). Thus, dyspnea should be carefully measured and plotted as a function of exercise intensity as reflected by increases in power output and ventilatory demand. Normative values have been recently published (Neder et al., 2020).

\section{Misinterpretation of a "Preserved" Peak $\mathrm{VO}_{2}$ as Evidence of Normality}

Peak $\dot{\mathrm{VO}}_{2}$ is highly dependent on the averaging method used to decrease the variability of breath-by-breath data. As expected, the shorter the averaging interval (and the lower the number of breaths considered for averaging), the higher the peak $\dot{\mathrm{VO}}_{2}$. Unfortunately, there are no consistent recommendations among existing guidelines on the averaging method. In practice, the most common settings range from 10 - to 60 -s periods: rolling averages of 15-20 s usually provide reproducible estimates of peak $\dot{\mathrm{VO}}_{2}$ in respiratory patients. Peak $\dot{\mathrm{VO}}_{2}$ is usually interpreted without the help of previous values for a meaningful longitudinal comparison. Thus, substantial loss of aerobic capacity might be missed if an impaired subject had, at an unknown baseline, a supra-normal peak $\dot{\mathrm{VO}}_{2}$ (Neder et al., 1998). A peak $\mathrm{V}_{2}$ within expected limits may coexist with extensive sub-maximal abnormalities; in fact, some of them (e.g., increased work of breathing) may increase "whole-body" $\dot{\mathrm{V}} \mathrm{O}_{2}$, bringing the peak value up to the limits of reference (Neder et al., 2018a). 

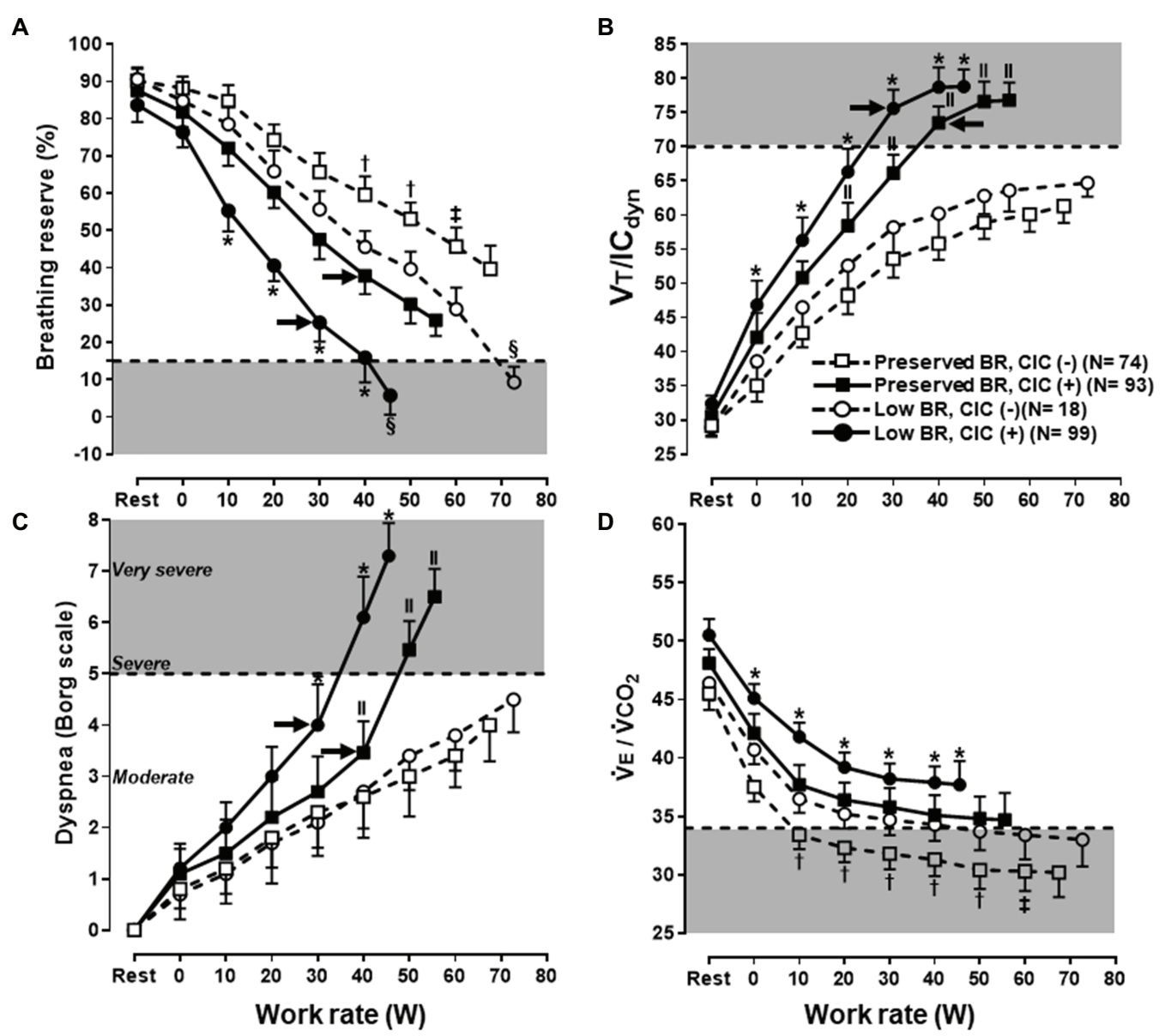

FIGURE 1 | Selected ventilatory and sensory responses to symptom limited incremental CPET in subjects under investigation for exertional dyspnea. Subjects were separated according to the combination of preserved or low peak breathing reserve (BR) vs. absence $(-)$ or presence $(+)$ of critical inspiratory constraints $(\mathrm{ClC})$. Note that a low BR (A) was found in subjects who either low or high levels of dyspnea (C); conversely, a sizeable fraction of subjects with preserved BR reported severe dyspnea. Regardless of the BR, subjects who develop CIC (B) and/or presented with poor ventilatory efficiency [high ventilation ( $\dot{V}$ E)/carbon dioxide output $\left(\dot{\mathrm{V}} \mathrm{O}_{2}\right)$ in $\mathbf{D}$ ] were consistently more dyspneic. Note the additive effects of these physiological abnormalities. Shaded areas represent the limits for a low BR, CIC, high dyspnea burden, and poor ventilatory efficiency, respectively. The arrows in (A-C) indicate the exercise intensities associated with an upward inflection in dyspnea ratings in $\mathrm{CIC}(+)$ subjects. See the text for further elaboration. Data are mean $\pm \mathrm{SEM}$. ${ }^{*} p<0.05$ vs. all groups; † vs. low $\mathrm{BR}, \mathrm{ClC}(-)$ and preserved $\mathrm{BR}, \mathrm{CIC}(+)$; $\ddagger$ vs. low BR, CIC(-); § vs. preserved BR, CIC(-) and preserved BR, CIC(+); II vs. low BR, CIC(-) and preserved BR, CIC(-). VT, tidal volume; IC, inspiratory capacity. Reproduced, with the permission of the publisher, from Neder (2019a).

\section{Ignoring the Effects of Obesity on the $\Delta \dot{\mathbf{V O}}_{2} / \Delta$ Work Rate Relationship}

Obese subjects expend more $\mathrm{O}_{2}$ to perform a given amount of external work as they need to displace a larger mass against gravity (Whipp and Davis, 1984). High $\dot{\mathrm{VO}}_{2} /$ work rate ratio in an obese subject may result in normal or even increased peak $\dot{\mathrm{V}}_{2}(\mathrm{~L} / \mathrm{min})$ despite a low peak work rate. This is not easily fixed by attempts to "correct" $\dot{\mathrm{VO}} 2$ for the mass displaced, i.e., total body and leg mass on treadmill and cycle ergometer, respectively (Neder et al., 2000). Expressing $\dot{\mathrm{VO}}_{2}$ as a function of total body mass $(\mathrm{ml} / \mathrm{min} / \mathrm{kg})$ is a more reasonable approach in treadmill-based tests. Conversely, it tends to penalize the obese exercising on a stationary bike (Neder et al., 1998). A valid alternative is to use reference values for peak $\dot{\mathrm{V}} \mathrm{O}_{2}$ based on height or ideal body weight and analyze results in percentage predicted (Hansen et al., 1984). In an obese subject showing low peak work rate but preserved peak $\dot{\mathrm{VO}}_{2}$, the former is likely to better reveal subject's functional capacity. This is particularly true if peak work rate is predicted from studies which included a large number of obese subjects (e.g., Koch et al., 2009; Myers et al., 2017).

\section{Failure to Recognize the Poor Diagnostic Performance of CPET in Indicating Cardiac Disease}

The accuracy at which the syndrome of impaired $\mathrm{O}_{2}$ delivery/ utilization reflects cardiocirculatory disease is based on the assumptions that: (a) the "downstream" (to the heart) consequences of these diseases are always present and (b) isolated or concurrent abnormalities at the muscle level can 
be differentiated from those occurring "upstream." Unfortunately, these premises are not consistently met in practice. It should also be recognized that non-invasive CPET only measures one of the three variables that are known to determine $\dot{\mathrm{V}}_{2}$ : heart rate (HR), stroke volume, and $\mathrm{O}_{2}$ extraction. Deficits in stroke volume can be compensated by increases in $\mathrm{HR}$ and/or $\mathrm{O}_{2}$ extraction; moreover, $\mathrm{HR}$ can be impaired in the absence of structural cardiac disease (see also below). Thus, in the absence of findings suggestive of severe ("out-of-proportion" to physical deconditioning) impairment in $\mathrm{O}_{2}$ delivery, the boundaries between inactivity and early cardiovascular disease are blurred in individual subjects. Thus, whereas a CPET deemed highly-suggestive of cardio-circulatory dysfunction deserves further investigation, a normal test in a subject with high pre-test likelihood of disease should be better seen as "not consistent with current moderate-to-severe dysfunction" (Neder et al., 2018a,b).

It should be explicitly recognized that a sizeable fraction of patients referred to clinical CPET have their resting and exertional HR under pharmacological or external control, e.g., $\beta$-blockers and pacemakers, respectively. Moreover, the prevalence of chronotropic incompetence has increased markedly in tandem with inactivity, obesity, and metabolic disorders (Brubaker and Kitzman, 2011). Thus, CPET variables based on HR, including the double-product (HR times systolic blood pressure), should be viewed with caution in these patients. Specifically, shallow $\Delta \mathrm{HR} / \Delta \dot{\mathrm{V}} \mathrm{O}_{2}$ and/or high $\mathrm{O}_{2}$ pulse should not be erroneously assumed as indicative of normality. Quite the opposite: a severely blunted $\Delta \mathrm{HR} / \Delta \dot{\mathrm{V}} \mathrm{O}_{2}$ in a CPET interrupted with objective and subjective evidences of maximal effort should be clinically valued as a potential source of exercise intolerance (Brubaker and Kitzman, 2011).

\section{Misdiagnosis of Mechanical-Ventilatory Limitation}

Maximal voluntary ventilation is a poor index of maximum breathing capacity during exercise (Babb and Rodarte, 1993). Regardless of the clinical scenario, relying on single cut-off of $\dot{\mathrm{V}} \mathrm{E} / \mathrm{MVV}$ ratio to rule out ventilatory limitation might be misleading. The ratio correlates poorly to exertional dyspnea in individual patients with both obstructive and restrictive disorders (O’Donnell et al., 2014; Faisal et al., 2016): as discussed above, it might serve as a metric of the quantitative ("how much $\dot{V}$ ") mechanisms of dyspnea, but it is insensitive to its qualitative foundations ("how appropriate $\dot{V}_{E}$ is performed"). Some dyspnoeic patients with chronic obstructive pulmonary disease (COPD), particularly those with mildmoderate airflow limitation (O'Donnell et al., 2016), stop exercising with preserved $\dot{\mathrm{V}} \mathrm{E} / \mathrm{MVV}$ but with clear evidences of constrained mechanics (Figure 1; O'Donnell et al., 2017; Neder et al., 2019b) Moreover, a still-preserved end-exercise $\dot{\mathrm{V}} \mathrm{E} / \mathrm{MVV}$ might be relevant for dyspnea and exercise intolerance if reached at a low peak work rate Thus, a high $\dot{\mathrm{V}} \mathrm{E} / \mathrm{MVV}$ might be valued to indicate low ventilatory reserves but a low $\dot{V}$ E/MVV should never be considered as the definitive proof that mechanical-ventilatory abnormalities are not relevant to patient's dyspnoea (Neder et al., 2019a).
The assessment of the operating lung volumes is based on the basic premise that a full inspiratory effort has been performed (Guenette et al., 2013). For instance, progressively lower IC due to inspiratory muscle weakness may be misinterpreted as indicative of dynamic hyperinflation. A common mistake is the belief that lack of IC decrement from rest signal for a normal response. Due to pronounced gas trapping at rest, however, patients with advanced COPD may not be able to further decrease IC during exercise (O'Donnell et al., 2017). A plateau in VT at higher operating lung volumes should raise the suspicion of the attainment of critical inspiratory constraints (Casaburi and Rennard, 2015); nevertheless, VT also tends to plateau after the respiratory compensation point (Neder and Stein, 2006). Thus, it is advisable to double-check whether such a plateau coincides or not with near-maximum end-inspiratory volumes, e.g., VT/exercise IC $\geq 0.8$ and/or end-inspiratory lung volume/ TLC $\geq 0.9$ (Guenette et al., 2013). The maximum flowvolume loop provides a poor frame of reference of the flow reserves at a given lung volume on effort, particularly in the presence of moderate to severe airflow limitation (Johnson et al., 1999). In practice, it is commonly valuable to assess changes on tidal expiratory limb's morphology (from convex to rectified or concave; Varga et al., 2016) and eventual leftward shifts in the tidal flow-volume loop as exercise progresses, i.e., dynamic hyperinflation.

\section{Under-Recognition of the Limitations of Non-invasive Assessment of Pulmonary Gas Exchange}

Due to the sigmoid shape of the $\mathrm{O}_{2}$ dissociation curve and the high noise-to-signal ratio of pulse oximeters on exertion, mildmoderate decrements in the arterial partial pressure for $\mathrm{O}_{2}\left(\mathrm{PaO}_{2}\right)$ might be missed by measurements of the arterial $\mathrm{O}_{2}$ saturation by this method $\left(\mathrm{SpO}_{2}\right)$. A pattern of impaired $\mathrm{O}_{2}$ delivery/ utilization might be seen in "respiratory" patients with severe exertional hypoxemia. The end-tidal partial pressure for $\mathrm{CO}_{2}$ $\left(\mathrm{PETCO}_{2}\right)$ is a particularly poor indicator of $\mathrm{PaCO}_{2}$ in patients with respiratory diseases (ERS Task Force et al., 2007). Thus, low $\mathrm{PeTCO}_{2}$ values may indicate high ventilation/perfusion or alveolar hyperventilation, i.e., dissimilar phenomena with opposite clinical implications. Conversely, a high $\mathrm{PeTCO}_{2}$ might either reflect the late emptying of poorly-ventilated units with higher alveolar $\mathrm{PCO}_{2}$ or alveolar hypoventilation (Hansen et al., 2007). In addition, a superficial and fast breathing pattern may decrease $\mathrm{PeTCO}_{2}$ since less alveolar air is sampled and the expiratory time becomes too short, i.e., there is not enough time for $\mathrm{PCO}_{2}$ to raise up to its highest value (Whipp and Ward, 1982). This explains why "automatic," non-invasive dead space/VT ratio (using $\mathrm{PETCO}_{2}$ ) underestimates the true dead space/VT in patients with ventilation-perfusion inequalities (Lewis et al., 1994), i.e., a "preserved" non-invasive dead space/VT is not useful to rule out poor gas exchange efficiency. Minimally-invasive or non-invasive alternatives to $\mathrm{PaCO}_{2}$ include capillary (arterialized) $\mathrm{PCO}_{2}$ (McLoughlin et al., 1992) or transcutaneous $\mathrm{PCO}_{2}$ (Hoffmann et al., 1990). If these techniques are used, serial measurements 
(at least three) are particularly useful to track the trajectory during incremental exercise (Rocha et al., 2017).

\section{Over- or Under Recognition of Chaotic Breathing Pattern/Dysfunctional Breathing}

There is a large heterogeneity on the presence and extension of dysfunctional breathing and hyperventilation across individuals, including the timing as related to rest and/or exercise. Detailed normative values for the timing and pattern of breathing at a given $\dot{V}_{E}$ have long been published (Neder et al., 2003); unfortunately, they are not commonly available in commercial software. As expected, differentiating a chaotic breathing pattern from the normal breath-by-breath noise might be complex if the plotted data is not adequately smoothed. Unless potential underlying abnormalities have been carefully excluded (e.g., neuromuscular disease, respiratory muscle weakness, asthma, and paradoxical vocal cord motion; Boulding et al., 2016), it is prudent to avoid labeling the phenomenon as "primary" or "merely psychogenic." Specific care should be taken to rule out a cyclic pattern of $\dot{V}_{E}$ oscillation which represents an important sign of cardiovascular disease and/or breathing control instability (periodic breathing; Leite et al., 2003) Relative to the later phenomenon, care should be taken to depict plot the $\dot{V}_{\mathrm{E}}$ axis (here, as an exception, vs. work rate or time) with sufficient resolution to appreciate the cycling changes. Owing to the fact that the ventilatoty and metabolic data oscillate in phase (Neder et al., 2003), period breathing is usually missed if only $\dot{\mathrm{V}} \mathrm{E}$ vs. $\dot{\mathrm{V}} \mathrm{CO}_{2}$ is examined.

\section{REFERENCES}

Arena, R., and Sietsema, K. E. (2011). Cardiopulmonary exercise testing in the clinical evaluation of patients with heart and lung disease. Circulation 123, 668-680. doi: 10.1161/CIRCULATIONAHA.109.914788

Babb, T. G., and Rodarte, J. R. (1993). Estimation of ventilatory capacity during submaximal exercise. J. Appl. Physiol. 74, 2016-2022. doi: 10.1152/ jappl.1993.74.4.2016

Beaver, W. L., Wasserman, K., and Whipp, B. J. (1986). A new method for detecting anaerobic threshold by gas exchange. J. Appl. Physiol. 60, 2020-2027. doi: 10.1152/jappl.1986.60.6.2020

Boulding, R., Stacey, R., Niven, R., and Fowler, S. J. (2016). Dysfunctional breathing: a review of the literature and proposal for classification. Eur. Respir. Rev. 25, 287-294. doi: 10.1183/16000617.0088-2015

Brubaker, P. H., and Kitzman, D. W. (2011). Chronotropic incompetence: causes, consequences, and management. Circulation 123, 1010-1020. doi: 10.1161/ CIRCULATIONAHA.110.940577

Campbell, E. J., and Howell, J. B. (1963). The sensation of breathlessness. Br. Med. Bull. 19, 36-40. doi: 10.1093/oxfordjournals.bmb.a070002

Casaburi, R., and Rennard, S. I. (2015). Exercise limitation in chronic obstructive pulmonary disease. The O'Donnell threshold. Am. J. Respir. Crit. Care Med. 191, 873-875. doi: 10.1164/rccm.201501-0084ED

Dumitrescu, D., and Rosenkranz, S. (2017). Graphical data display for clinical cardiopulmonary exercise testing. Ann. Am. Thorac. Soc. 14, S12-S21. doi: 10.1513/AnnalsATS.201612-955FR

ERS Task Force, Palange, P., Ward, S. A., Carlsen, K. -H., Casaburi, R., Gallagher, C. G., et al. (2007). Recommendations on the use of exercise testing in clinical practice. Eur. Respir. J. 29, 185-209. doi: 10.1183/09031936.00046906

Faisal, A., Alghamdi, B. J., Ciavaglia, C. E., Elbehairy, A. F., Webb, K. A., Ora, J., et al. (2016). Common mechanisms of dyspnea in chronic interstitial and obstructive lung disorders. Am. J. Respir. Crit. Care Med. 193, 299-309. doi: $10.1164 / \mathrm{rccm} .201504-08410 \mathrm{O}$

\section{CONCLUSION}

There remains a long way for CPET to be widely recognized as a clinically-useful tool for the investigation of the mechanisms of dyspnea and exercise intolerance in patients with chronic cardiorespiratory disease. As discussed in this Perspective, we have advanced substantially in the identification of common pitfalls for testing interpretation. We are also more aware of CPET limitations, particularly in this era of advanced imaging and invasive diagnostic procedures. A sober recognition of these limitations, associated with a final report free from technicalities and convoluted terminology, is crucial to enhance the credibility of CPET in the eyes of the practicing physician.

\section{DATA AVAILABILITY STATEMENT}

The original contributions presented in the study are included in the article/supplementary material, further inquiries can be directed to the corresponding author.

\section{AUTHOR CONTRIBUTIONS}

JAN wrote the first draft. All authors were involved in the manuscript preparation, contributed to the article, and approved the submitted version.
Guenette, J. A., Chin, R. C., Cory, J. M., Webb, K. A., and O'Donnell, D. E (2013). Inspiratory capacity during exercise: measurement, analysis, and interpretation. Pulm. Med. 2013:956081. doi: 10.1155/2013/956081

Hansen, J. E., Sue, D. Y., and Wasserman, K. (1984). Predicted values for clinical exercise testing. Am. Rev. Respir. Dis. 129, S49-S55. doi: 10.1164/ arrd.1984.129.2P2.S49

Hansen, J. E., Ulubay, G., Chow, B. F., Sun, X. -G., and Wasserman, K. (2007). Mixed-expired and end-tidal $\mathrm{CO}_{2}$ distinguish between ventilation and perfusion defects during exercise testing in patients with lung and heart diseases. Chest 132, 977-983. doi: 10.1378/chest.07-0619

Hoffmann, U., Essfeld, D., and Stegemann, J. (1990). Comparison of arterial, end-tidal and transcutaneous $\mathrm{PCO}_{2}$ during moderate exercise and external $\mathrm{CO}_{2}$ loading in humans. Eur. J. Appl. Physiol. 61, 1-4. doi: 10.1007/BF00236685

Johnson, B. D., Weisman, I. M., Zeballos, R. J., and Beck, K. C. (1999). Emerging concepts in the evaluation of ventilatory limitation during exercise: the exercise tidal flow-volume loop. Chest 116, 488-503. doi: 10.1378/chest.116.2.488

Jones, N. (1988). Clinical exercise testing. 3rd Edn. Philadelphia, PA: W.B Saunders Company.

Kearon, M. C., Summers, E., Jones, N. L., Campbell, E. J., and Killian, K. J. (1991). Effort and dyspnoea during work of varying intensity and duration. Eur. Respir. J. 4, 917-925.

Killian, K. J., and Campbell, E. J. (1983). Dyspnea and exercise. Annu. Rev. Physiol. 45, 465-479. doi: 10.1146/annurev.ph.45.030183.002341

Killian, K. J., Summers, E., Jones, N. L., and Campbell, E. J. (1992). Dyspnea and leg effort during incremental cycle ergometry. Am. Rev. Respir. Dis. 145, 1339-1345. doi: 10.1164/ajrccm/145.6.1339

Koch, B., Schäper, C., Ittermann, T., Spielhagen, T., Dörr, M., Völzke, H., et al. (2009). Reference values for cardiopulmonary exercise testing in healthy volunteers: the SHIP study. Eur. Respir. J. 33, 389-397. doi: 10.1183/09031936.00074208

Laveneziana, P., Ward, S., Neder, J. A., and Poberezhets, V. (2017). Clinical exercise testing: basic principles and practice. Breathe 13, 163-164. doi: $10.1183 / 20734735.009717$ 
Leite, J. J., Mansur, A. J., de Freitas, H. F. G., Chizola, P. R., Bocchi, E. A., Terra-Filho, M., et al. (2003). Periodic breathing during incremental exercise predicts mortality in patients with chronic heart failure evaluated for cardiac transplantation. J. Am. Coll. Cardiol. 41, 2175-2181. doi: 10.1016/ s0735-1097(03)00460-1

Lewis, D. A., Sietsema, K. E., Casaburi, R., and Sue, D. Y. (1994). Inaccuracy of noninvasive estimates of VD/VT in clinical exercise testing. Chest 106, 1476-1480. doi: 10.1378/chest.106.5.1476

Mahler, D. A., and O'Donnell, D. E. (2015). Recent advances in dyspnea. Chest 147, 232-241. doi: 10.1378/chest.14-0800

Marciniuk, D. D., Johnson, B. D., Neder, J. A., and O'Donnell, D. E. (2013). Cardiopulmonary exercise testing. Pulm. Med. 2013:686104. doi: 10.1155/ 2013/686104

McLoughlin, P., Popham, P., Linton, R. A., Bruce, R. C., and Band, D. M. (1992). Use of arterialized venous blood sampling during incremental exercise tests. J. Appl. Physiol. 73, 937-940. doi: 10.1152/jappl.1992.73.3.937

Myers, J., Kaminsky, L. A., Lima, R., Christle, J. W., Ashley, E., and Arena, R. (2017). A reference equation for normal standards for $\mathrm{VO}_{2}$ max: analysis from the fitness registry and the importance of exercise national database (FRIEND registry). Prog. Cardiovasc. Dis. 60, 21-29. doi: 10.1016/j. pcad.2017.03.002

Neder, J. A., Arbex, F. F., Alencar, M. C. N., O’Donnell, C. D. J., Cory, J., Webb, K. A., et al. (2015). Exercise ventilatory inefficiency in mild to endstage COPD. Eur. Respir. J. 45, 377-387. doi: 10.1183/09031936.00135514

Neder, J. A., Berton, D. C., Marillier, M., Bernard, A. -C., O’Donnell, D. E., and Canadian Respiratory Research Network (2019a). The role of evaluating inspiratory constraints and ventilatory inefficiency in the investigation of dyspnea of unclear etiology. Respir. Med. 158, 6-13. doi: 10.1016/j.rmed.2019.09.007

Neder, J. A., Berton, D. C., Marillier, M., Bernard, A. -C., O’Donnell, D. E., and Canadian Respiratory Research Network (2019b). Inspiratory constraints and ventilatory inefficiency are superior to breathing reserve in the assessment of exertional dyspnea in COPD. COPD 16, 174-181. doi: 10.1080/ 15412555.2019.1631776

Neder, J. A., Berton, D. C., Nery, L. E., Tan, W. C., Bourbeau, J., O’Donnell, D. E., et al. (2020). A frame of reference for assessing the intensity of exertional dyspnoea during incremental cycle ergometry. Eur. Respir. J. 56:2000191. doi: 10.1183/13993003.00191-2020

Neder, J. A., Berton, D. C., Rocha, A., Arbex, F., Alencar, M. C., Degani-Costa, L. H., et al. (2018a). "Abnormal patterns of response to incremental CPET" in 2018 clinical exercise testing European respiratory monograph. eds. P. Palange, P. Laveneziana, J. A. Neder and S. A. Ward (Sheffield, UK: European Respiratory Society), 34-58.

Neder, J. A., Dal Corso, S., Malaguti, C., Reis, S., De Fuccio, M. B., Schmidt, H., et al. (2003). The pattern and timing of breathing during incremental exercise: a normative study. Eur. Respir. J. 21, 530-538. doi: 10.1183/09031936.03.00045402

Neder, J. A., Laveneziana, P., Ward, S. A., and Palange, P. (2018b). "CPET in clinical practice. Recent advances, current challenges and future directions" in 2018 clinical exercise testing european respiratory monograph. eds. P. Palange, P. Laveneziana, J. A. Neder and S. A. Ward (Sheffield, UK: European Respiratory Society), $\mathrm{x}-\mathrm{xxv}$.

Neder, J. A., Nery, L. E., Andreoni, S., Sachs, A., and Whipp, B. J. (2000). Oxygen cost for cycling as related to leg mass in males and females, aged 20 to 80. Int. J. Sports Med. 21, 263-269. doi: 10.1055/s-2000-8885

Neder, J. A., Nery, L. E., Bagatin, E., Lucas, S. R., Anção, M. S., and Sue, D. Y. (1998). Differences between remaining ability and loss of capacity in maximum aerobic impairment. Braz. J. Med. Biol. Res. 31, 639-646. doi: 10.1590/ S0100-879X1998000500006
Neder, J. A., and Stein, R. (2006). A simplified strategy for the estimation of the exercise ventilatory thresholds. Med. Sci. Sports Exerc. 38, 1007-1013. doi: 10.1249/01.mss.0000218141.90442.6c

O’Donnell, D. E., Elbehairy, A. F., Berton, D. C., Domnik, N. J., and Neder, J. A. (2017). Advances in the evaluation of respiratory pathophysiology during exercise in chronic lung diseases. Front. Physiol. 8:82. doi: 10.3389/fphys.2017.00082

O’Donnell, D. E., Laveneziana, P., Webb, K., and Neder, J. A. (2014). Chronic obstructive pulmonary disease: clinical integrative physiology. Clin. Chest Med. 35, 51-69. doi: 10.1016/j.ccm.2013.09.008

O’Donnell, D. E., Milne, K. M., Vincent, S. G., and Neder, J. A. (2019). Unraveling the causes of unexplained dyspnea: the value of exercise testing. Clin. Chest Med. 40, 471-499. doi: 10.1016/j.ccm.2019.02.014

O'Donnell, D. E., Neder, J. A., and Elbehairy, A. F. (2016). Physiological impairment in mild COPD. Respirology 21, 211-223. doi: 10.1111/resp.12619

Plachi, F., Balzan, F. M., Fröhlich, L. F., Gass, R., Mendes, N. B., Schroeder, E., et al. (2020). Exertional dyspnoea-ventilation relationship to discriminate respiratory from cardiac impairment. Eur. Respir. J. 55:1901518. doi: 10.1183/13993003.01518-2019

Plataki, M., Sands, S. A., and Malhotra, A. (2013). Clinical consequences of altered chemoreflex control. Respir. Physiol. Neurobiol. 189, 354-363. doi: 10.1016/j.resp.2013.04.020

Rocha, A., Arbex, F. F., Sperandio, P. A., Souza, A., Biazzim, L., Mancuso, F., et al. (2017). Excess ventilation in COPD-heart failure overlap: implications for dyspnea and exercise intolerance. Am. J. Respir. Crit. Care Med. 196, 1264-1274. doi: 10.1164/rccm.201704-0675OC

Varga, J., Casaburi, R., Ma, S., Hecht, A., Hsia, D., Somfay, A., et al. (2016). Relation of concavity in the expiratory flow-volume loop to dynamic hyperinflation during exercise in COPD. Respir. Physiol. Neurobiol. 234, 79-84. doi: 10.1016/j.resp.2016.08.005

Wasserman, K., Hansen, J., Sue, D., and Whipp, B. (1987). Principles of exercise testing and interpretation. Philadelphia, PA: Lea \& Ferbiger.

Wasserman, K., and Whipp, B. J. (1975). Exercise physiology in health and disease. Am. Rev. Respir. Dis. 112, 219-249. doi: 10.1164/arrd.1975.112.2.219

Wasserman, K., Whipp, B. J., Koyl, S. N., and Beaver, W. L. (1973). Anaerobic threshold and respiratory gas exchange during exercise. J. Appl. Physiol. 35, 236-243. doi: 10.1152/jappl.1973.35.2.236

Weisman, I. M., and Zeballos, R. J. (1996). Clinical evaluation of unexplained dyspnea. Cardiologia 41, 621-634.

Whipp, B. J. (1977). The hyperpnea of dynamic muscular exercise. Exerc. Sport Sci. Rev. 5, 295-311. doi: 10.1249/00003677-197700050-00010

Whipp, B. J., and Davis, J. A. (1984). The ventilatory stress of exercise in obesity. Am. Rev. Respir. Dis. 129, S90-S92. doi: 10.1164/arrd.1984.129.2P2. S90

Whipp, B. J., and Ward, S. A. (1982). Cardiopulmonary coupling during exercise. J. Exp. Biol. 100, 175-193.

Conflict of Interest: The authors declare that the research was conducted in the absence of any commercial or financial relationships that could be construed as a potential conflict of interest.

Copyright (C) 2021 Neder, Phillips, Marillier, Bernard, Berton and O’Donnell. This is an open-access article distributed under the terms of the Creative Commons Attribution License (CC BY). The use, distribution or reproduction in other forums is permitted, provided the original author(s) and the copyright owner(s) are credited and that the original publication in this journal is cited, in accordance with accepted academic practice. No use, distribution or reproduction is permitted which does not comply with these terms. 